\title{
An analysis of the geographic distribution of acute-care hospitals and accessibility to care - based on the Japanese DPC database KB Ishikawa*1 and S Matsuda²
}

\author{
Address: ${ }^{1}$ Systems Development Section, National Cancer Center, Tokyo, Japan and ${ }^{2}$ Public Health, University of Occupational and Industrial \\ Medicine, Fukuoka, Japan \\ * Corresponding author
}

from 25th Patient Classification Systems International (PCSI) Working Conference

Fukuoka, Japan. II-I4 November 2009

Published: 5 November 2009

BMC Health Services Research 2009, 9(Suppl I):AI8 doi:I0.II86/I472-6963-9-SI-AI8

This abstract is available from: http://www.biomedcentral.com/I472-6963/9/SI/AI8

(c) 2009 Ishikawa and Matsuda; licensee BioMed Central Ltd.

\section{Introduction}

Geographic accessibility to care depends not only on the distribution of hospitals, but also on the services that each hospital provides. This study illustrates methods to utilize nationally collected hospital casemix information to analyze accessibility to care.

\section{Methods}

Hospital casemix data published by the Ministry of Health, Labor and Welfare (DPC [Diagnosis Procedure Combination] survey data) is used to construct a database of acute-care hospitals. Hospitals are then geo-coded, using their addresses, to calculate drive-times to a geographic mesh. The resulting hospital-to-mesh drive-time table is used to analyze accessibility to services in each region or prefecture.

\section{Results}

The 2007 DPC survey data consisted of 1,428 hospitals ( $16 \%$ of all hospitals), 457,000 beds (50\% of all hospital beds), and four million discharges for the latter half of the year 2007. Coverage rates of population within $90 \mathrm{~min}-$ utes of these hospitals were over $88.9 \%$ for all prefectures, with 33 out of 47 prefectures having rates over $99 \%$. However, when the volume of services provided by each hospital was considered, population coverage showed a large disparity between prefectures and hospital services. The results also suggested the existence of a monopolistic provision of specific services in a few prefectures.

\section{Conclusion}

An analysis of the geographic accessibility to care relies deeply on a description of hospital services. Nationally collected information, such as the Japanese DPC survey data, is crucial in the pursuit of closing the care gap that exists in the real world. 